\title{
Editorial to the Liège Colloquium Special Issue: Long-term studies in oceanography - a celebration of 50 years of science at the Liège Colloquium (1969 - 2018)
}

\author{
Aida Alvera-Azcárate ${ }^{1} \cdot$ Charles Troupin $^{1} \cdot$ Hughes Goosse $^{2} \cdot$ Michael J. McPhaden $^{3} \cdot$ Jean-Marie Beckers $^{1}$
}

Accepted: 27 October 2020 / Published online: 5 December 2020

(C) This is a U.S. government work and not under copyright protection in the U.S. 2020

\section{Introduction}

The 50th edition of the International Liège Colloquium on Ocean Dynamics was held in Liège (Belgium) from 28 May to 1 June 2018. We took this opportunity to review the advances made in studying the oceans during the last several decades. In particular, this edition was dedicated to long-term studies in oceanography. Our knowledge about the ocean, the availability and quality of data and the tools to study the ocean have changed dramatically over these past 50 years. The ocean plays a crucial role in the regulation of the Earth's climate. As climate change poses an unprecedented threat to the Earth environment, studies focusing on the long-term variation of the ocean and its response to climate change have therefore become essential to understand and monitor the Earth climate.

Long-term ocean in situ observing systems are essential to assess the state of the ocean. These data allow studying the evolution of the ocean environment, estimate the rate of recent changes, and determine the influence of climate patterns on the state of the ocean. With several decades of data accessible, at unprecedented temporal and spatial

Responsible Editor: Jörg-Olaf Wolff

Aida Alvera-Azcárate

a.alvera@ulg.ac.be

1 AGO-GHER, University of Liège, Allée du Six Aout, 17, Sart Tilman, Liège, 4000, Belgium

2 Earth and Life Institute, Université Catholique de Louvain, Louvain-la-Neuve, Belgium

3 NOAA/Pacific Marine Environmental Laboratory, Seattle, WA, 98115, USA resolutions, remote sensing data have also become essential for the study of long-term changes in the ocean. Reprocessing of several decades of Earth Observation data provide a tool for a unique understanding of the evolution of the ocean state.

Ocean reanalyses integrate observations and models to study the ocean and its evolution over recent decades, and provide the most complete estimate of the state of the ocean in space and time. Ocean reanalyses are used as initial conditions for operational estimations of the ocean state, for short-term predictions aiming at studying specific processes, for seasonal and decadal predictions, and for climate-related activities.

Efforts to maintain these long-term initiatives and to make the data easily and openly available to the scientific community have permitted to advance our understanding of the evolution of the ocean over the last decades. These efforts should continue to ensure science-based decisions on the management of our oceans.

The 50th edition of the International Liège Colloquium had 96 participants from 20 countries (group photos in Fig. 1). A total of 98 presentations were given (33 oral, 65 posters) as well as 7 keynote talks, distributed over 6 topical sessions. Two poster prizes were awarded. The Jacques Nihoul Poster Award (chosen by representatives of the scientific committee) was given to Roy El Hourany for the work "Reconstruction of phytoplankton group variability using diagnostic pigments retrieved from satellite observations". The public poster award was given to Katia Mallil for the work "Evolution of water mass characteristics in the Algerian gyres". Lunch breaks were organized for early career scientists that wished to interact with senior scientists, keynote speakers and scientific committee members. These encounters were highly appreciated by the early career scientists that participated. 
Fig. 1 Attendants to the 50th International Liège Colloquium on Ocean Dynamics, a during talks and $\mathbf{b}$ celebrating the 50th Liège Colloquium during the ice breaker
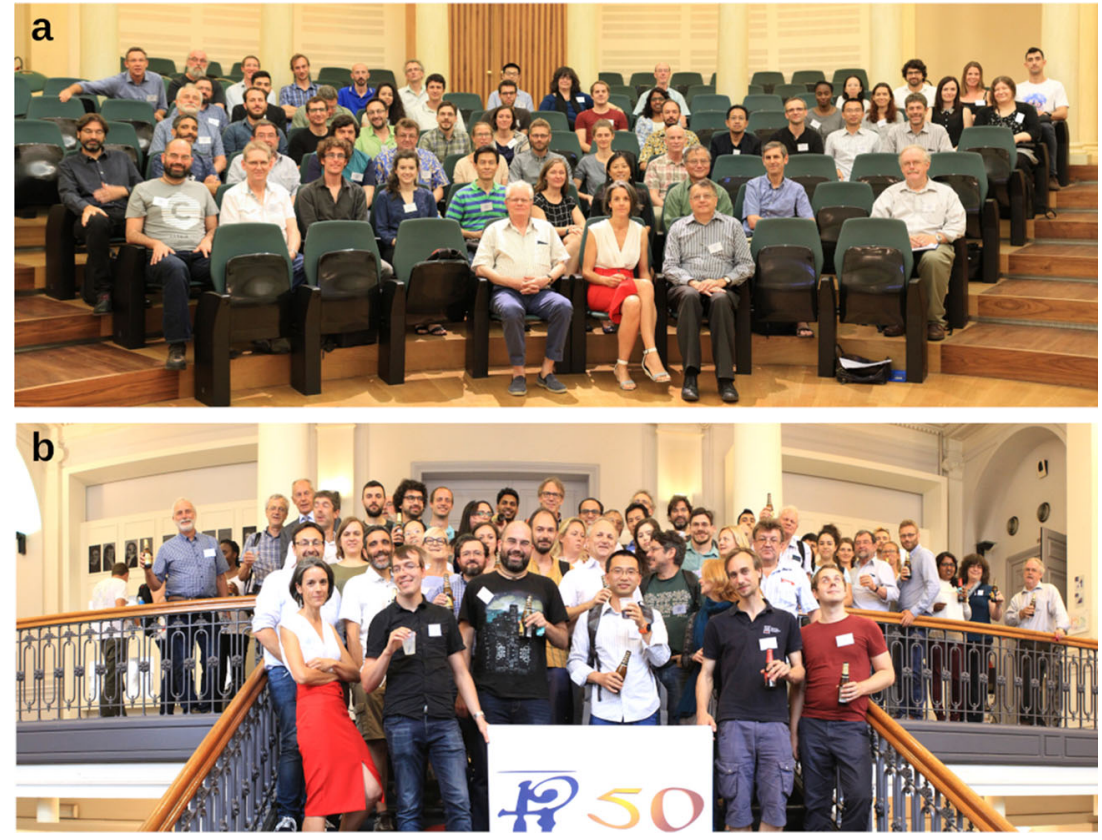

This special edition contains five articles. Reverdin et al. (2019) study the variability of the North Atlantic extratropical and subpolar gyre using 120 years of surface temperature, salinity and density in situ data while (Platov et al. 2019) used model simulations to analyse trends in Arctic ice. Bode et al. (2019) uses a 28-year long record of chlorophyll concentration in the NW of Spain to assess the influence of nutrients and upwelling intensity in the temporal variability, timing and intensity of spring blooms. Salat et al. (2019) present a 45-year long times series of oceanographic and meteorological observations. These long-term in situ times series are very valuable for the validation of multidecadal trends, and to serve as ground truth for satellite observations. Finally, Huynh et al. (2020) analyse the spatial and temporal variability of chlorophyll concentration in the South China Sea using more than 10 years of satellite data.

\section{History of participation to fifty years of the Liège Colloquium}

An essential role in the history of the Liège Colloquium was of course played by Professor Jacques Nihoul who, with a few friends from the turbulence community, started a yearly meeting to share ideas. He organized the first of such meetings on 1969. Since the 3rd Edition, the event was officially made an annual event, as explained in these words: "The increasing success of the First and Second Colloquia on Ocean Hydrodynamics organized at the University of Liège commanded that they be continued. [...] It is a great joy for the Organizing Committee to realize that, in the same time, the continuation of the Colloquia was deeply desired by all the participants and that their gratifying determination was indeed answerable for making, from now on, the Liège Colloquium on Ocean Hydrodynamics an annual meeting". Professor Nihoul was a prolific writer and eager to disseminate the outcomes of the meetings (the famous blue books for those who remember them!), so the colloquium quickly became known and expanded. It was a time when the former USSR scientific community had only few occasions to join international meetings and Jacques Nihoul was able to brand the Liège Colloquium as one of the major meetings where the cold war was transformed into heated discussions, favoured by the organization of lateevening "discussions". Changing annually the topic of the colloquium ensured that different scientists were attracted every year which then met with the long-term supporters, allowing for new interactions. From the University of Liège side it was also the place where our young Ph.D. students had the opportunity to meet the specialists in their domain in a privileged way, very often leading to a post-doc collaboration.

We take advantage of this special issue to present an analysis of the participation data from the available past issues and mention a few anecdotes concerning the event.

The colloquium logo The millennium of the PrinceBishopric of Liège (a state of the Roman Empire, ruled by the Bishop of Liège) was celebrated in 1980 by the city and the province of Liège. The symbol of the celebration was designed by a local artist, Willy Warnier. It allies the bishop cane with the prince's sword, representing the two facets of the prince-bishops. This symbol was then yielded to Jacques 
Nihoul, and forty years later it is still the official logo of the colloquium (Fig. 2).

Participation Compiling a list with all the participants of a conference is something done routinely nowadays, but it was unfortunately not always like this. In order to obtain the list of participants of the colloquium for each year we had at our disposal:

- The special issues from 1970 to 1989 , either in paper or in electronic format, which included a list of participants.

- The participant lists prepared by the secretariat from 2000 on.

This results in some missing, and probably unrecoverable, information in the 1990s. The lists from the paper issues were encoded, the consistency names and surnames were checked and additional editing was performed to the participant affiliation in order to improve the discovery by automatic geolocators (i.e. deduction of country from institute name and address). Finally, country names were adapted in order to fit with the list of existing countries in 2018. When available, the numbers of submitted abstracts and of published papers were also collected. The processed data consisted of text files storing the name, affiliation, city and country of each participant of the editions that could be recovered.

We found a total of 2420 unique participants, totaling 3309 participations. Seventy one different countries were represented during the last half-century, with more than 500 participations from the USA, 440 from France and 300 from the UK. Nineteen countries were represented only one time. Concerning the most regular participants (discarding those coming from Belgium), we have one scientist from Grenoble who participated 12 times and 6 scientists from various countries who participated 7 times each. Again those numbers do not take into account the missing data

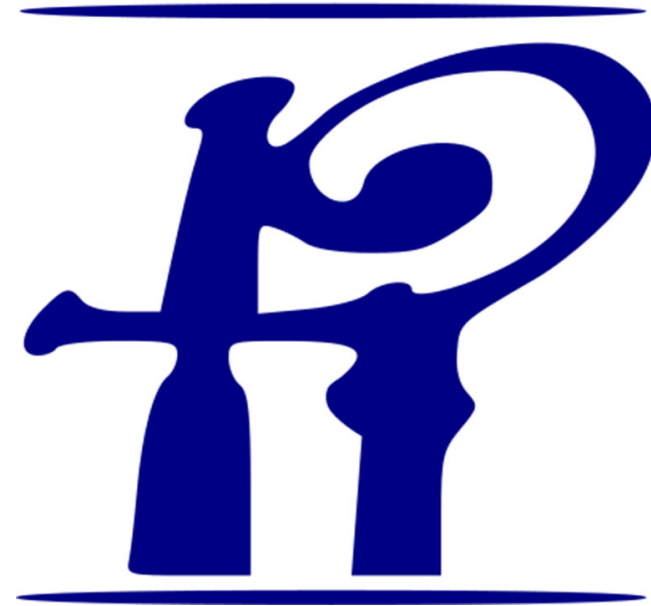

Fig. 2 The Liège Colloquium logo from the 1990s. The most distant participant came from the University of Tasmania, located more than $17,016 \mathrm{~km}$ from Liège.

The information is summarized in the form of interactive maps (https://gher-ulg.github.io/Liege-Colloquium/ participationMap.html) and time series (https://gher-ulg. github.io/Liege-Colloquium/participationTime.html) that will be updated every year. As an example, Fig. 3 shows the number of participants per country and place of origin.

Topics The first edition was organized with the very general topic "The hydrodynamics equations applicable to the ocean", then the next years the topics were focused on specific aspects of the oceanography, as shown in the full list available at https://gher-ulg.github.io/Liege-Colloquium/ topics.html. Combining all the colloquium titles from the last 50 years allows one to highlight recurring topics covered, discarding the obvious "ocean" and "sea" words that appeared 11 and 8 times, respectively:

- "marine", "modelling" and "hydrodynamics" appeared in 10 editions,

- "turbulence" in 8 editions,

- "processes" in 7 editions and

- "scale" (accompanied by an adjective like submeso-, small, meso-, synoptic and global), in 5 editions.

Though the colloquium always favours the quality of the topics over the quantity of participants, it is worth mentioning that the 3 most attended editions were:

- "Primary production in the ocean: from the synoptic to the global scale" in 2013, with 220 participants from 35 countries.

- "Submesoscale Processes: Mechanisms, Implications and new Frontiers" in 2016, with 202 participants from 25 countries.

- "Low oxygen environments in marine, estuarine and fresh waters" in 2014, with 157 participants from 31 countries.

If we analyse the participation by decades, we have:

- In the 1970s: "Marine Forecasting Predictability and Modelling in Ocean Hydrodynamics" in 1978, with 78 participants from 16 countries.

- In the 1980s: "Coupled ocean-atmosphere models" in 1984, with 133 participants from 20 countries.

- In the 2000s: "Exchange Processes at the Ocean Margins" in 2000, with 143 participants from 21 countries.

- In the 2010s: "Submesoscale Processes: Mechanisms, Implications and new Frontiers" in 2016, with 202 participants from 25 countries.

The missing data in the 1990s did not make it possible to find which edition was the most attended overall. The 


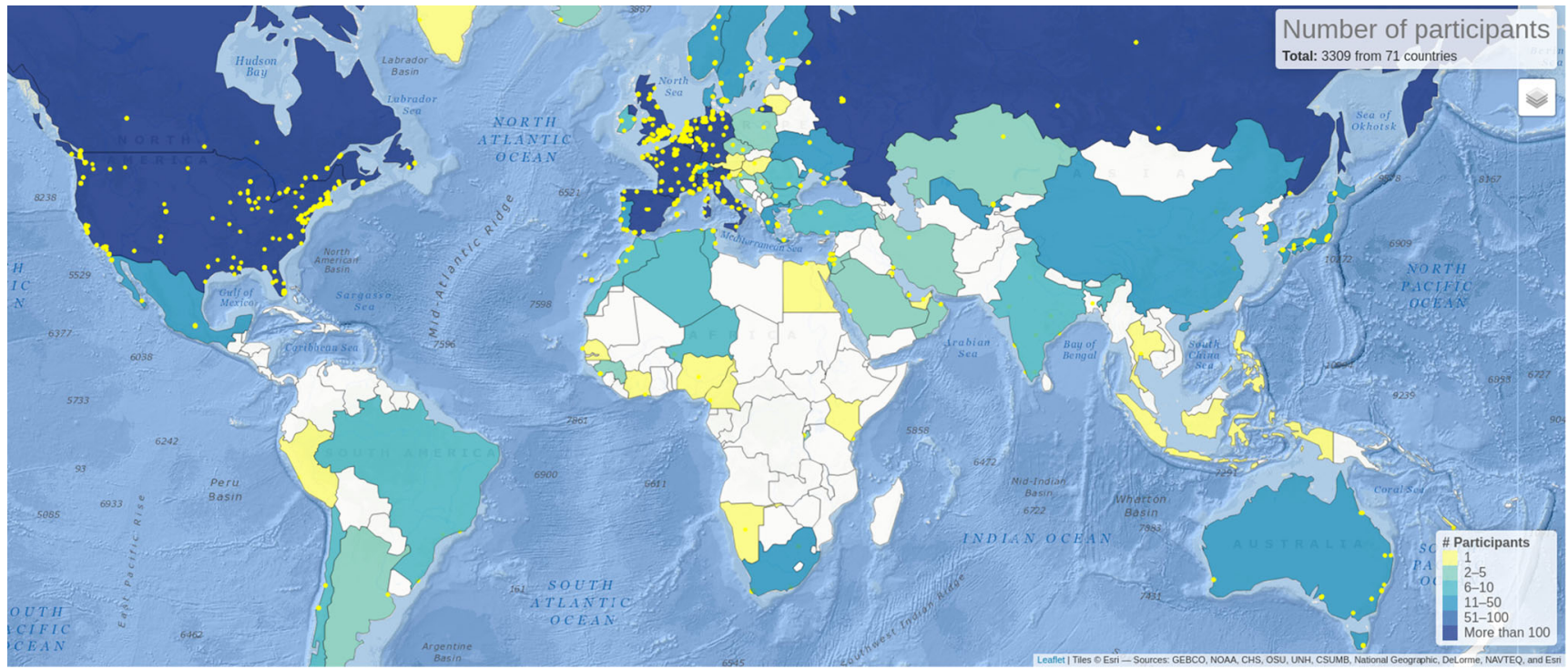

Fig. 3 Number of participants per country

1988 edition on "Mesoscale/synoptic coherent structures in geophysical turbulence" has the special issue with the largest numbers of articles: fifty-one!

Organizers The Liège Colloquium counts each year with the invaluable participation of one or several external scientific organizers, whose dedication and help we sincerely thank. We also would like to thank the members of the scientific committees.

\section{And the next 50 years?}

Trying to predict what the Liège Colloquium will be in 50 years time is, of course, an impossible task. We do hope that the Liège Colloquium will remain the place to share the latest scientific developments in ocean dynamics from people from all around the world. There are some topics that will certainly be of growing interest over the coming years, as climate change irremediably shapes our environment. Research into climate mitigation, adaptation and applications will become more widespread. Computers will become ever more powerful, permitting finely detailed simulations of the ocean, atmosphere and earth system. The increasing use of autonomous platforms and robotics will allow us to observe the ocean in places with historically very few data. Observational technologies will become smaller, more powerful, and more accurate, permitting definition of ocean features at finer spatial and temporal scales. We will see further development of "intelligent" communications between autonomous observing platforms, which will allow targeted measuring strategies and planning, for example in the aftermath of natural disasters.
Research based on satellite data will continue its development and its increasing role in decision making and strategic planning. Development of new satellite sensors will allow the measurement of new variables, and the accuracy and resolution will be improved. Integrating long term observations of physical variables with biogeochemichal ones, in particular using models as in reanalyses, will provide a more consistent view of ocean changes. With the surge in the amount of data available for scientists, machine learning and artificial intelligence techniques will become widespread. All these developments will allow for a better understanding of the ocean dynamics and its role in the earth system at finer and finer scales, and with that our capability for predicting the state of the ocean with increased accuracy. Finally, ocean science is likely to become more collaborative, interdisciplinary and international in scope as the problems oceanographers tackle increase in complexity and societal relevance.

It may also be that over the course of the next 50 years people will read this and smile at our naivety.

Acknowledgements The organizers of the 50th edition of the Liège Colloquium, and in the name of the scientific committee and of the organizing committee, we want to thank the sponsors of this event for their valuable support: F.R.S.-FNRS (Belgium), Belspo (Belgium), Règion Wallonne (Belgium), University of Liège (Belgium), ESA. This is PMEL contribution number 5175 .

\section{References}

Bode A, Álvarez M, Ruíz-Villarreal M, Varela M (2019) Changes in phytoplankton production and upwelling intensity off A Coruña (NW Spain) for the last 28 years. Ocean Dyn 69:861-873 
Huynh H, Alvera-Azcárate A, Beckers J-M (2020) Analysis of surface chlorophyll a associated with sea surface temperature and surface wind in the South China Sea. Ocean Dyn 70:139-161

Platov G, Golubeva E, Kraineva M, Malakhova V (2019) Modeling of climate tendencies in arctic seas based on atmospheric forcing eof decomposition. Ocean Dyn 69:747-767

Reverdin G, Friedman A, Chafik L, Holliday N, Szekely T, Valdimarsson H, Yashayaev I (2019) North Atlantic extratropical and subpolar gyre variability during the last 120 years: a gridded dataset of surface temperature, salinity, and density. Part 1: dataset validation and RMS variability. Ocean Dyn 69: 385-403

Salat J, Pascual J, Flexas M, Chin T, Vazquez-Cuervo J (2019) Fortyfive years of oceanographic and meteorological observations at a coastal station in the NW Mediterranean: a ground truth for satellite observations. Ocean Dyn 69:1067-1084 